\title{
Assessment of bronchial inflammation using an automated cell recognition system based on colour analysis
}

\author{
P. Berger, J. Lavallée, R. Rouiller, F. Laurent, R. Marthan, J.M. Tunon-de-Lara
}

Assessment of bronchial inflammation using an automated cell recognition system based on colour analysis. P. Berger, J. Lavallée, R. Rouiller, F. Laurent, R. Marthan, J.M. Tunon-deLara. (C) ERS Journals Ltd 1999.

ABSTRACT: The aim of this study was to develop an automated system of cell recognition based upon colour analysis suitable for microscopic examination of bronchial inflammation.

Human bronchi obtained from 17 patients undergoing thoracotomy were embedded in glycolmethacrylate to perform immunohistochemistry with antibodies against: neutrophil elastase, tryptase, chymase, eosinophil cationic protein, CD68, CD3 and immunoglobulin $\mathbf{E}$. The image analysis system calculates three independent criteria (optic density, hue density, hue) combined with morphological parameters to specifically recognize a positive staining. This automated analysis was applied to the study of bronchial inflammation in smokers and nonsmokers in terms of the absolute number of cells and the expression of different markers by a single cell.

The use of these criteria enabled the characterization of a positive stain on single (intraclass correlation coefficient $($ ICC $)=0.88$ or serial $($ ICC $=0.84)$ sections. Cell counts obtained by the automated system were highly reproducible. Regarding bronchial inflammation, it was found that the number of inflammatory cells was significantly higher in smokers than in nonsmokers, the majority of these cells bearing immunoglobulin $\mathbf{E}$.

These results demonstrate that such computerized analysis of colours is a valuable method for quantifying inflammatory cells in bronchial tissue and for analysing the expression of different markers by a single cell.

Eur Respir J 1999; 14: 1394-1402.
Laboratoire de Physiologie Cellulaire Respiratoire, INSERM (E-9937), Université Victor Ségalen Bordeaux 2, Bordeaux, France.

Correspondence: J.M. Tunon de Lara, Laboratoire de Physiologie Cellulaire Respiratoire, Université Victor Ségalen Bordeaux 2, 146 rue Léo Saignat, 33076 Bordeaux Cedex, France.

Fax: 33557571501

Keywords: Bronchus

colour image

human

immunohistochemistry

inflammation

serial section

Received: October 211998

Accepted after revision June 111999

This study was supported by grants from the Institut Pneumologique d'Aquitaine, the Ministère de 1'Environnement - ADEMEINERIS (No. 9593017-97034), the Conseil Régional d'Aquitaine (980301115), and from Laboratoire Astra-France.
A variety of bronchial diseases such as asthma or chronic obstructive pulmonary disease (COPD) are related to tissue infiltration by inflammatory cells that have been mainly identified by means of immunohistochemistry and/ or in situ hybridization [1-11]. Multiple studies performed on asthmatic tissue have allowed the characterization of this cell infiltration, and a growing number of the studies performed in smokers and subjects suffering from COPD are based on the analysis of inflammatory cells in bronchial tissue.

In all of the above mentioned studies, inflammatory cells have been observed using light microscopy. Using a microscope, a trained observer can discriminate between cells, provided that these have been stained with a chromogen corresponding to a defined colour. However, quantification of cells is time consuming, tedious and subjective, leading to both inter- and intraobserver variabilities. Automated image analysis appears to be suitable to overcome these disadvantages. Moreover, numeric acquisition allows the extraction of additional complementary information from microscopic images. For example, it has been demonstrated that a black and white image analysis with an appropriate grey-scale enables the quantification of protein expression in tissue [12] and can be used for automated counting of nuclei [13]. Comprehensive automated analyses of colour images have been scarcely used so far since, in a first approach, the optic density i.e., black and white analysis of a colour image, is sufficient to discri- minate between a positive staining and a negative control. Nevertheless, LAMAZIERE et al. [14] have provided substantial evidence that a colour analysis could compare the distribution of two antigens stained by two different colours. Such analysis is based on the fact that a primary colour i.e., red, green or blue, contains both chromatic and nonchromatic information that can be used to define specific criteria of measurement. However, these criteria that only estimate the surface distribution of a defined colour cannot be used for an automated cell counting since other parameters of cell recognition, such as accurate discrimination between close overlapping colours, or independency of variations in transillumination light intensity, are required.

The aim of the present study was 1) to develop an automated system of cell recognition based upon colour analysis suitable for microscopic examination of bronchial mucosa inflammation using immunohistochemistry, and 2) to apply this automated method to the analysis of the inflammatory cells in bronchial mucosa of smokers and nonsmokers.

\section{Materials and methods}

\section{Subjects}

Human lung was obtained at thoracotomy as previously described $[15,16]$ from 17 patients undergoing resection 
Table 1. - Patient characteristics

\begin{tabular}{lcc}
\hline & Nonsmokers $(\mathrm{n}=6)$ & Smokers $(\mathrm{n}=9)$ \\
\hline Sex M/F & $4 / 3$ & $10 / 0$ \\
Age yrs & $66 \pm 3.3$ & $56 \pm 4.5$ \\
Smoking pack-yrs & - & $35 \pm 5.5$ \\
FEV1 \% pred & $100 \pm 5.8$ & $93 \pm 5.7$ \\
PEF25-75\% pred & $76 \pm 8.4$ & $66 \pm 7.6$ \\
sGaw \% pred & $155 \pm 31.1$ & $221 \pm 54.4$ \\
TLC \% pred & $108 \pm 5.4$ & $98 \pm 4.8$ \\
RV \% pred & $123 \pm 11.8$ & $105 \pm 5.8$ \\
$P \mathrm{a}, \mathrm{O}_{2}$ mmHg & $85 \pm 4.8$ & $72 \pm 5.2$ \\
\hline
\end{tabular}

Data are presented as mean \pm SEM. M: male; F: female; FEV1: forced expiratory volume in one second; FEF25-75: forced midexpiratory flow; $s G$ aw: specific airway conductance; TLC: total lung capacity; $\mathrm{RV}$ : residual volume; $\mathrm{Pa}_{\mathrm{a}} \mathrm{O}_{2}$ : arterial oxygen tension. $(1 \mathrm{mmHg}=0.133 \mathrm{kPa})$

for pulmonary carcinoma. Patients were neither atopic nor asthmatic, and were divided into two groups, i.e. smokers and nonsmokers. Patient characteristics, assessed prior to surgery, are presented in table 1 .

\section{Tissue processing}

Human bronchi were processed as previously described $[16,17]$. Briefly, segments of distal bronchi $0.5-1 \mathrm{~mm}$ in ID dissected from a grossly normal part of the specimen were cut into small fragments of $2^{3} \mathrm{~mm}$. Specimens were fixed overnight in ice-cooled acetone. After $7 \mathrm{~h}$ incubation at $4^{\circ} \mathrm{C}$ in glycolmethacrylate (GMA) monomers (Polysciences, Northampton, UK), embedding resin was prepared with benzoyl peroxide (Polysciences), GMA monomers, and $N, N$-dimethylaniline (Polysciences) and polymerized overnight at $4^{\circ} \mathrm{C}$. Serial $2 \mu \mathrm{m}$-sections were cut with ultramicrotome and incubated overnight with a primary monoclonal antibody $(\mathrm{mAb})$ specific for a defined cell phenotype: antihuman neutrophil elastase (Dako, Trappes, France), antihuman tryptase AA1 [18], antihuman chymase (Chemicon, Souffelweyersheim, France), antihuman monocytes CD68 (Dako), antihuman activated eosinophils (EG2; Pharmacia \& Upjohn, Saint-Quentinen-Yvelines, France), antihuman lymphocytes CD3 (Dako) and anti-human immunoglobulin (Ig)E directed against the C 82 domain of the heavy chain (Immunotech, Marseille, France). Control slides were treated similarly, in one case omitting the primary $\mathrm{mAb}$, and in the other employing an unrelated antibody of the same isotype. The streptavidin-biotin-peroxidase method was used with amino-ethyl carbamazole (Sigma, Saint-Quentin-Fallavier, France) as the substrate to develop a peroxidedependent red colour reaction at $37^{\circ} \mathrm{C}$. The sections were counterstained with Mayer's hematoxylin.

\section{Image analysis system}

Light microscopy was performed using an Optiphot microscope (Nikon, Tokyo, Japan), with $\times 10, \times 20, \times 40$ objective lenses. Microscopic images could be simultaneously observed through the oculars and on the output of the image digitizer. The images were scanned by a (charge coupled device; CCD) XC-999P colour video camera (Sony, Tokyo, Japan) linked to the digitizer via a phase alternation line (PAL) connection. Each videoframe was converted into $512 \times 512 \times 3$ array of pixels scaled on 8 bits, corresponding to a surface of $180,372 \mu \mathrm{m}^{2}$. The image processing board was inserted inside an $133 \mathrm{MHz}$ personal computer and linked to a video monitor (ADI, Taiwan).

\section{Cell recognition system}

The image analysis system using Quancoul(C) software (Quant'Image, 1997; Bordeaux, France) calculates three independent criteria i.e., optic density (OD), hue density (HD), hue (H) from the three primary colours i.e., red, green and blue. OD corresponds to the black and white view of the colour image in terms of pure illumination normalized by the dynamic, from black (0) to white (255). $\mathrm{HD}$ is an index of dilution of the observed colour, which remains stable under different illuminations with a range of available values, from the absence of colour (0) to full colour (255). $\mathrm{H}$ is the pure dominant wavelength in the spectral distribution of the observed colours. A colour scale ascribes to each colour a particular value: red (0), yellow (42), green (84), cyan (127), blue (170), magenta (212) and red (255). Both microscope and camera were calibrated using specific dyes (Nikkon, Tokyo, Japan) and by the adjustment of microscope light and/or the modification of both gain and offset of the camera. Predetermined colours were created by the software which calculates the values of the $\mathrm{OD}, \mathrm{HD}, \mathrm{H}$ on a set of images chosen as representative for a $\mathrm{mAb}$. Two colour masks were established by adjustment of minimum and maximum threshold values for these parameters: a restricted calibration was defined by $\mathrm{OD}=20-100, \mathrm{HD}=170-250$ and $\mathrm{H}=180$ 255 and a wide calibration by $\mathrm{OD}=20-120, \mathrm{HD}=160-250$ and $\mathrm{H}=170-255$.

Morphological criteria, i.e. surface, orientation, or width/length ratio, were defined in order to characterize the light microscopic aspect of the cell. When requested, these morphological criteria could be used by adjustment of minimum and maximum threshold values. All of these values were validated by a pathologist, i.e., the colour mask corresponds to a typical positive staining obtained with a defined antibody. In order to recognize different parts of a whole cell and to count it as an entire cell, a proximity index was established by the expert, according to the mean size of the cells.

The use of primary colours (i.e., red, green and blue) or the OD as criteria of analysis did not allow the discrimination of a positive stain from the background signal since histograms were limited to one mode (fig. 1a-d). By contrast, $\mathrm{HD}$ and $\mathrm{H}$ distribution histograms allowed the significant separation of different modes using a peak detection algorithm [19] combined with a thresholding technique [20] and could be successfully used for a particular staining recognition (fig. 1e and f). Regarding the coefficient of dispersion (COD) histogram, significantly higher values were found for both HD and H (16.8, $10.9 \%$ respectively) than for primary colours $(3.0,4.0$, $3.4 \%$ respectively) or OD (i.e., 3.4\%).

The use of both HD and H combined with OD measurement and morphological parameters enabled the characterization of a coloured cell (i.e. nucleus, cytoplasmic and/or membrane staining), the storage of these criteria, and the specific recognition of the cell by the 
a)

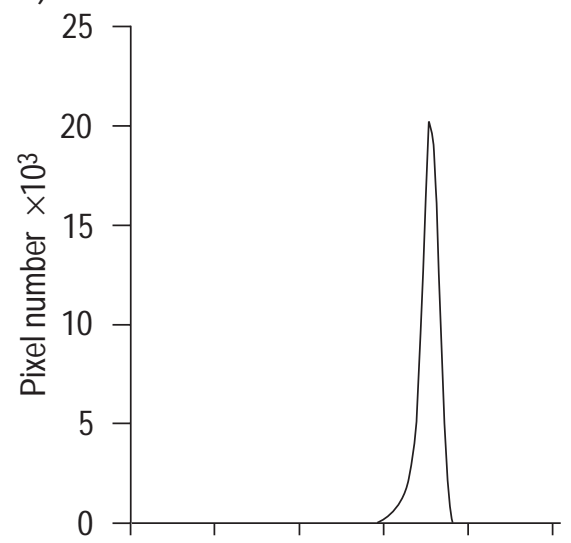

d)

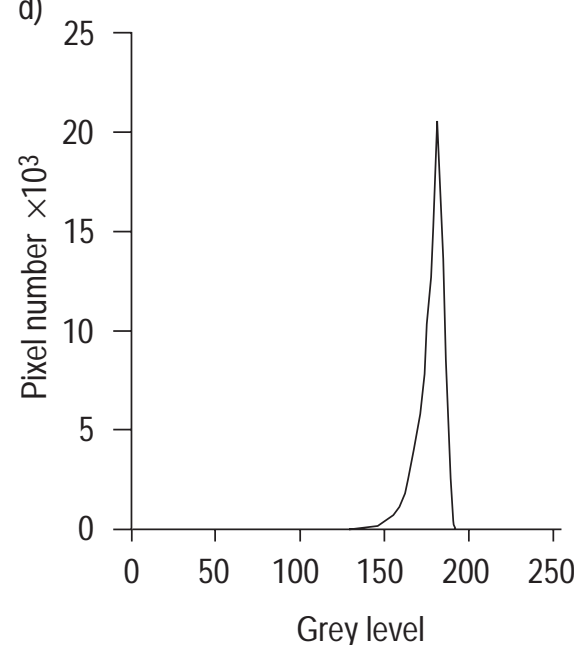

b)

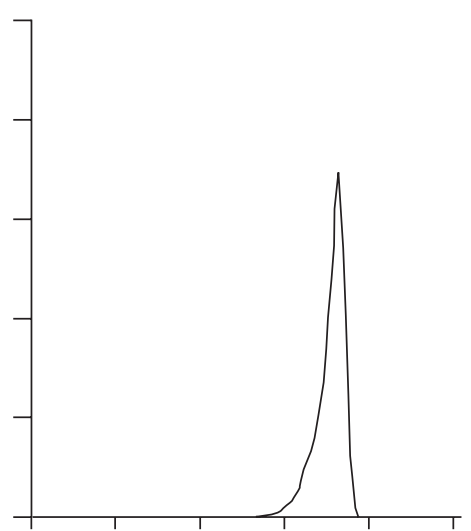

e)

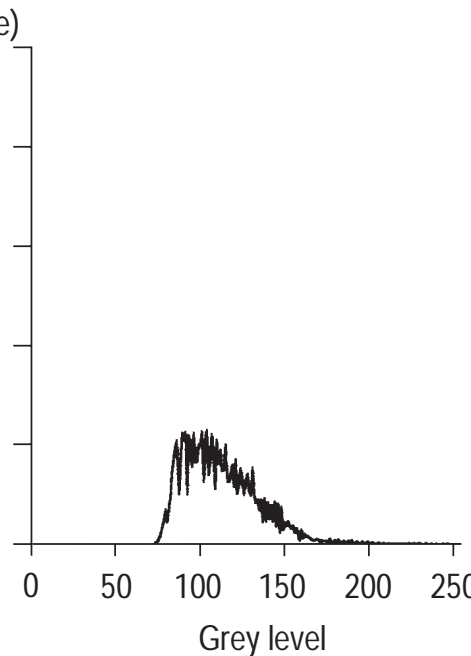

c)

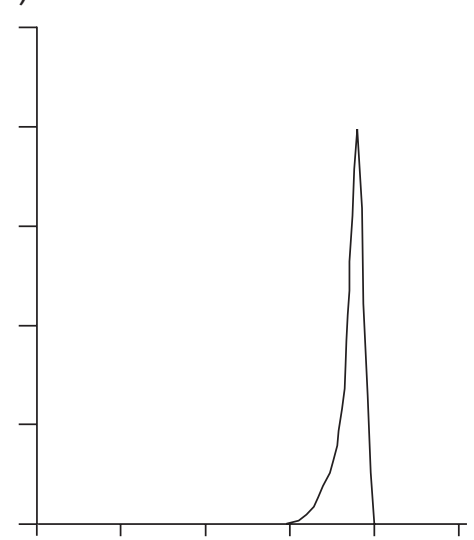

f)

Fig. 1. - Distribution histograms of the three primary colours: a) red; b) green; c) blue compared with those of the three parameters: d) optical density; e) hue density; and $\mathrm{f}$ ) hue, for the same digitized image of a representative human bronchus specimen, stained with antihuman immunoglobulin E.

software. This automated method was applied to the measurement of inflammatory cell infiltration of human bronchial mucosa, and to automatically count several phenotypes defined by their specific staining.

\section{Automated cell count analysis}

The automatic cell count was systematically applied to adjacent sections, using two different predetermined colours with a wide and a restricted calibration. The mean of both counts was then calculated. Colocalization of cells in adjacent sections was performed with the $\times 10$ objective lense using a specific process. The first step consisted of the acquisition of an image of the reference section in which an area of interest was selected (fig. 2a). A reference mask was then drawn using anatomical marks (e.g., epithelium, gland, vessel, etc.), and saved in its position. A specific blur index, i.e., a circular zone delimited around the cell staining, was validated by the operator, at a diameter of $10 \mu \mathrm{m}$. The second step consisted of selecting the predetermined colour corresponding to the $\mathrm{mAb}$ used on this section in order to prepare the count of positive cells on this image. When required, additional parameters including surface $\left(\mu \mathrm{m}^{2}\right)$, orientation $\left(^{\circ}\right)$, width/ length ratio $(\%)$ or proximity between different parts of a whole cell $(\mu \mathrm{m})$, could be used to define positive staining.
In the third step, the same area of interest was localized by the operator on the adjacent section, and superimposed on the reference mask (fig. 2b). The image was adjusted using several tools provided by the software (e.g., translation, rotation, inversion left/right or top/bottom). After adjustment, the modified image corresponding to the reference mask was saved on the computer. The fourth step was identical to the second step, i.e., the predetermined colour corresponding to the staining of the mAb used on this section was specifically selected. Steps three and four could be repeated if required, with additional adjacent sections. Step five consisted of an automated cell count on each section, using all of the predetermined criteria. When all of the images were processed, the final was performed, that step consisted of the automated counting of cells selected as positive on different serial sections, according to the defined blur index. The results are shown on the reference image (fig. 2c), and can be given on a data table.

As a control, cell counts were performed using standard light microscopy. Each specimen automatically examined by the software was also examined in a blinded fashion by two independent trained observers using $\times 200$ and $\times 400$ magnifications. Colocalization of positive staining in adjacent sections was analysed by the same two observers, using a manual superimposition as previously described 

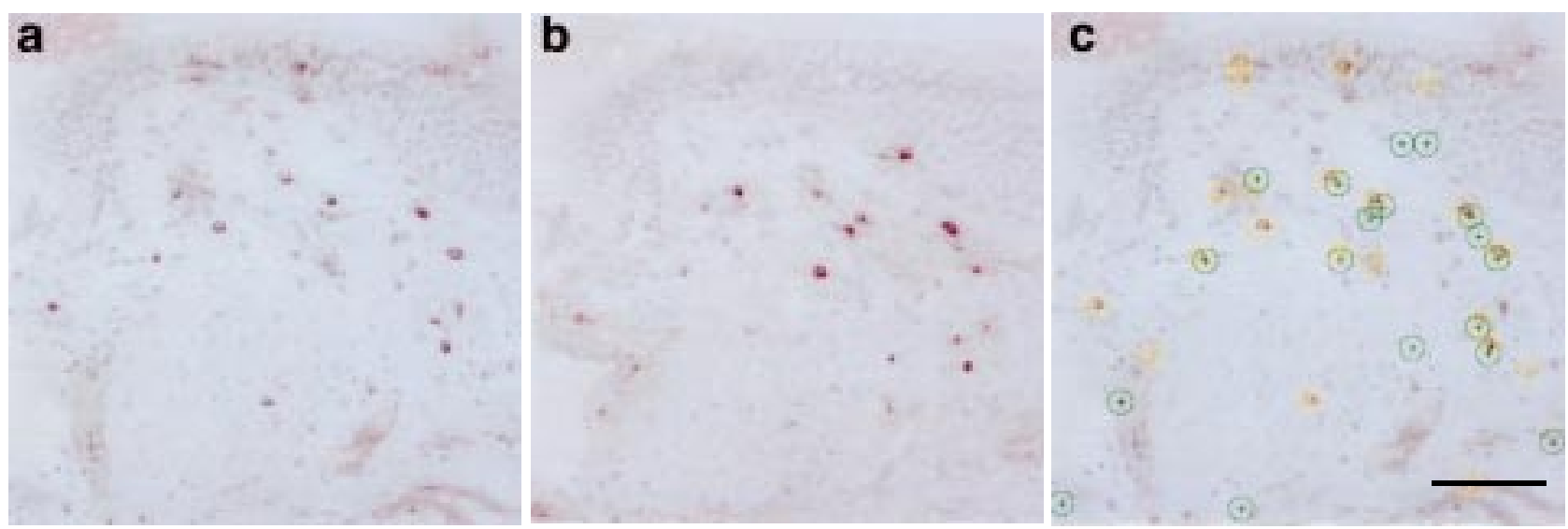

Fig. 2. - Automated analysis of adjacent sections stained with different monoclonal antibodies. Digitized images from optical microscopic views of a representative human bronchus specimen stained with: a) antihuman immunoglobulin E (IgE) de2; b) antihuman chymase; and c) antihuman IgE de2 with yellow crosses indicating anti-IgE-positive cells and green crosses indicating antichymase positive cells. Circles indicate the blur index. Internal scale bar $=100 \mu \mathrm{m}$.

[21]. Briefly, a delimited zone is projected on a white paper sheet using a camera lucida. Positive cells are drawn on the paper with a specific colour or using a specific symbol. The corresponding zone on the adjacent section is delimited by the observer and orientated to be superimposed onto the previous one. Positive cells for the second marker are drawn using a different colour or symbol and compared to that previously indicated as positive.

\section{Automated analysis of bronchial inflammation}

An automated analysis of bronchial inflammation was performed in smoker and nonsmoker subjects. Cells staining positively for each $\mathrm{mAb}$ were counted in all of the specimens excluding alveoli. The total area examined was calculated by delineating the area of the bronchial section on a video interactive display system $(\times 100$ magnification). A compartmental analysis was also performed delineating bronchial epithelium, submucosa and the smooth muscle layer. Cells counts were expressed as number of cells $\cdot \mathrm{mm}^{2}$ of tissue.

\section{Statistical analysis}

Regarding the three primary colours and the criteria calculated from the numeric acquisition, the distributions were defined by the median, corresponding to the 50th percentile of the data set, and by the COD corresponding to the following formula: $\mathrm{COD}=\left(\Sigma \mid \mathrm{x}_{\mathrm{i}}-\right.$ median $\left.\mid / \mathrm{n}\right) /$ median, where $x_{i}$ is the value of each data, and $n$ the number of data.

The reliability and validity of the automated cell count system was analysed using the following different approaches:

1) Since cell counts were not normally distributed, the Spearman correlation coefficient between nontransformed cell counts was calculated for two representative microscopic screens per subject, at a $\times 100$ magnification.

2) Intraclass correlation coefficient (ICC) using logtransformed values defined as (m.SSB-SST)/((m-1).SST) was calculated ( $\mathrm{m}$ is the number of observations per subject, SSB the sum of squares between subjects and SST the total sum of squares) [22].

3) The coefficient of variation (CV) was defined as the standard deviation divided by the mean, was also determined [23].

4) Finally, a Bland and Altman analysis of log-transformed values was performed. Means of cell counts between automatic and manual counts were plotted against their differences [24]. The Pearson correlation coefficient was calculated between means and differences of cell counts.

Cell counts expressed as number of cells $\cdot \mathrm{mm}^{2}$ obtained in smokers and nonsmokers were compared using an unpaired Wilcoxon rank test.

\section{Results}

Comparison of automated system with observer analysis

In order to validate the automatic cell count, this measurement was compared with that performed by two different trained observers using light microscopy (table 2). In terms of absolute number of cells, there was a strong correlation between the automated analysis and that performed by both observers (fig. 3a). In addition, the Bland and Altman analysis [24] did not show any correlation between means and differences for individual cell counts (fig. $4 a, b)$.

Applying this method to anti-AA1/antichymase, antiIgE/anti-AA1 or anti-IgE/antichymase double stainings (table 2), a strong correlation was also found between the software and both observers (fig. 3b), without any correlation between means and differences for individual cell counts in both methods (fig. 4c, d).

In addition, the multiple series of automatic cell counts using the same digitized images allowed the obtention of a $100 \%$ reproducibility of cell counting.

\section{Automated analysis of bronchial inflammation}

The analysis of inflammatory cell distribution within the bronchial wall was performed using the automated cell 
Table 2. - Correlation matrix of inflammatory cell number

\begin{tabular}{|c|c|c|c|c|c|c|c|c|c|c|}
\hline \multirow[b]{2}{*}{ Cell type } & \multicolumn{3}{|c|}{ Q/Obs 1} & \multicolumn{3}{|c|}{$\mathrm{Q} / \mathrm{Obs} 2$} & \multicolumn{3}{|c|}{$\mathrm{Q} / \mathrm{Obs} 1$ and 2} & \multirow{2}{*}{$\begin{array}{c}\text { Cells* } \\
\text { n }\end{array}$} \\
\hline & $\mathrm{r}$ & $\begin{array}{c}\mathrm{CV} \\
\%\end{array}$ & ICC & $\mathrm{r}$ & $\begin{array}{c}\mathrm{CV} \\
\%\end{array}$ & ICC & $\mathrm{rM}$ & $\begin{array}{c}\text { CVM } \\
\%\end{array}$ & ICC & \\
\hline \multicolumn{11}{|l|}{ Isolated sections } \\
\hline All & 0.90 & 35 & 0.89 & 0.84 & 34 & 0.83 & 0.89 & 34 & 0.88 & 112 \\
\hline NE+ & 0.85 & 19 & 0.82 & 0.81 & 20 & 0.75 & 0.88 & 19 & 0.79 & 15 \\
\hline $\mathrm{AA} 1+$ & 0.92 & 16 & 0.90 & 0.94 & 17 & 0.92 & 0.95 & 16 & 0.92 & 17 \\
\hline Chymase+ & 0.92 & 29 & 0.91 & 0.93 & 29 & 0.92 & 0.94 & 29 & 0.92 & 17 \\
\hline CD68+ & 0.96 & 23 & 0.94 & 0.96 & 23 & 0.91 & 0.97 & 23 & 0.94 & 15 \\
\hline EG2+ & 0.73 & 50 & 0.68 & 0.52 & 42 & 0.49 & 0.68 & 44 & 0.66 & 15 \\
\hline CD3+ & 0.92 & 32 & 0.85 & 0.85 & 33 & 0.71 & 0.90 & 32 & 0.82 & 16 \\
\hline $\mathrm{d} \varepsilon 2+$ & 0.72 & 33 & 0.72 & 0.55 & 26 & 0.50 & 0.71 & 29 & 0.62 & 17 \\
\hline \multicolumn{11}{|l|}{ Adjacent sections } \\
\hline All & 0.91 & 47 & 0.90 & 0.79 & 43 & 0.75 & 0.88 & 45 & 0.84 & 35 \\
\hline AA1/chymase & 0.92 & 45 & 0.86 & 0.78 & 38 & 0.54 & 0.86 & 41 & 0.74 & 11 \\
\hline $\mathrm{d} \varepsilon 2 / \mathrm{AA} 1$ & 0.95 & 46 & 0.91 & 0.91 & 45 & 0.84 & 0.94 & 45 & 0.89 & 12 \\
\hline $\mathrm{d} \varepsilon 2 /$ chymase & 0.94 & 54 & 0.91 & 0.88 & 49 & 0.82 & 0.93 & 51 & 0.86 & 12 \\
\hline
\end{tabular}

*: logarithmically transformed. Q: Quancoul image analysis; Obs: observer; M: interobserver mean; r: Pearson correlation coefficient between Q and Obs or Q and M; CV: coefficient of variation; ICC: intraclass correlation; AA1: antimast cell tryptase; CD68: human monocytes/macrophages; EG2: human eosinophils; CD3: human lymphocytes; de2: Antihuman immunoglobulin E.
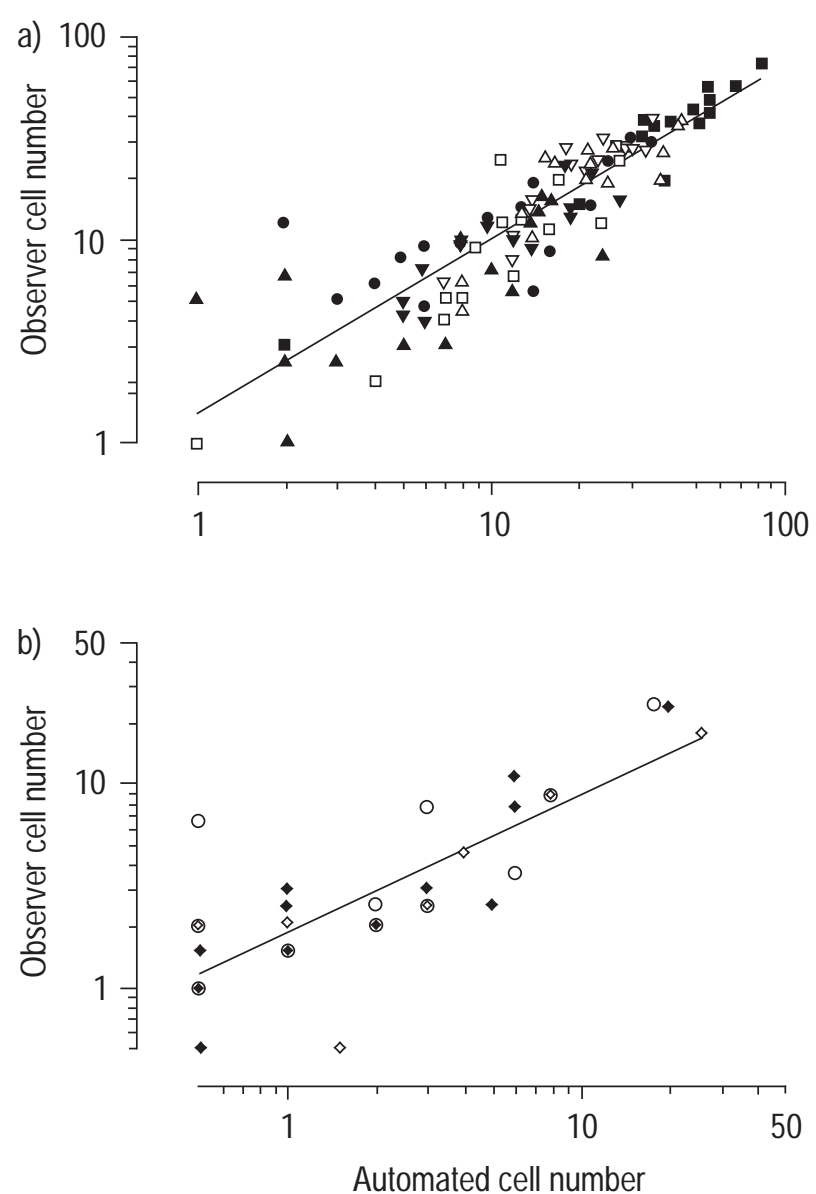

Fig. 3. - Automated cell counts within the bronchial wall $(n=17)$ plotted against the mean counts performed by two trained independent observers. a) cells positive for immunoglobulin E (IgE) de2 ( $)$, antimast cell tryptase (AA1) $(\nabla)$, antichymase $(\boldsymbol{\nabla})$, CD3 $(\square)$, CD68 $(\boldsymbol{\square})$, antineutrophil elastase $(\triangle)$, and human eosinophils $(\boldsymbol{\Delta})$; and b) cells positive for $\operatorname{IgE} \mathrm{d} \varepsilon 2 / \mathrm{AA} 1(\diamond), \mathrm{d} \varepsilon 2 /$ antichymase $(\diamond)$, and AA1/ antichymase $(\mathrm{O})$ in adjacent sections. count system for both cell counting and examination of adjacent sections. Results of cell counts in terms of inflammatory cell density are presented in table 3 . The total number of inflammatory cells (i.e. neutrophils + mast cells + macrophages + eosinophils + lymphocytes) was significantly higher in smokers than in nonsmokers (median values $=591.6$ and 392.7 , respectively; $p=0.02$ ). Regarding individual values for the different cell phenotypes the difference was not statistically significant.

Automated analysis of adjacent sections was applied to the examination of $\operatorname{IgE}$ bearing cells and mast cell phenotypes. The total number of IgE positive cells within the bronchial wall was significantly higher in smokers than in nonsmokers. IgE bearing cells distribution was also significantly different between the groups since their density was higher in submucosa and lower in epithelium of smoking subjects. Protease immunostaining on adjacent sections was analysed to describe the distribution of mast cell subtypes (i.e. mast cells containing tryptase and chymase termed MCTC and mast cells containing tryptase alone termed MCT) in bronchial tissue (fig. 5). No difference was found in the mast cell distribution within the whole bronchial wall between smokers and nonsmokers, the majority of mast cells being identified as MCT. The compartmental analysis revealed however, that smokers had a lower density of MCTC within the epithelial layer when compared with nonsmokers.

\section{Discussion}

This study reports a novel method suitable for analysing cell infiltration in tissues, based upon the automated recognition of staining colours obtained by immunohistochemistry. This system enables the automatic counting of inflammatory cells in bronchial mucosa and the identification of different markers expressed by a single cell. Results obtained by such a method are not different from those 

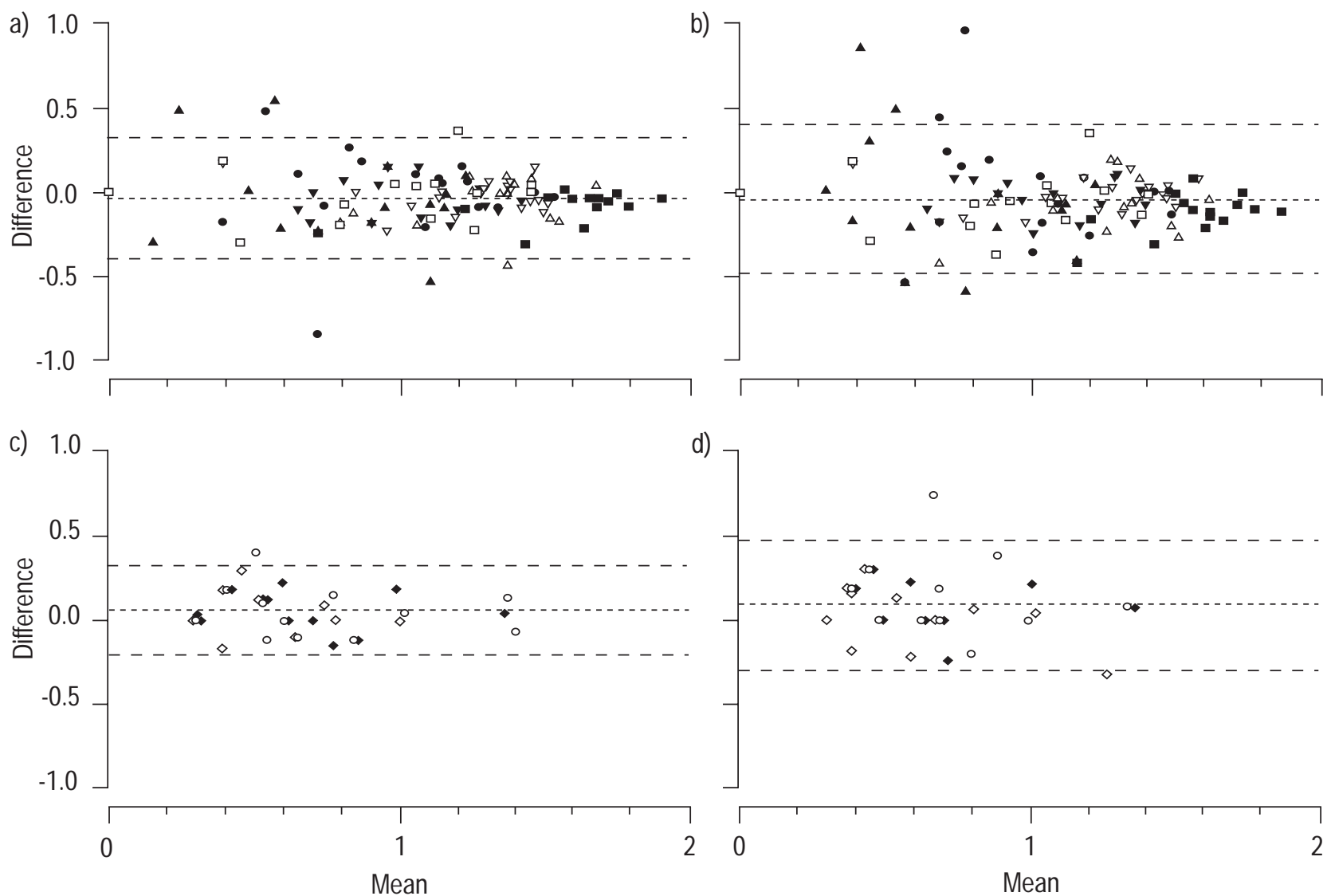

Fig. 4. - Means of cell counts between the automated and manual methods are plotted against their differences according to Bland and Altman analysis in adjacent sections: a, c) observer 1; and b, d) observer 2. 0 : Immunoglobulin E (IgE) de2; $\nabla$ : antimast cell tryptase (AA1); $\square$ : CD3; $\mathbf{\square}$ : CD68; $\boldsymbol{\nabla}$ : antichymase; $\triangle$ : antineutrophil elastase; $\boldsymbol{\Lambda}$ : human eosinophils; $\diamond$ : IgE de2/AA1; $\diamond:$ d $\varepsilon 2$ antichymase; $\bigcirc:$ AA1/antichymase.

obtained by two independent trained observers and can thus be routinely collected.

Immunohistochemistry is widely used to identify cell phenotypes and their markers in bronchial tissue. For this purpose, immunoenzymatic staining methods are frequently performed resulting in a coloured reaction which is evaluated using light microscopy. There are numerous advantages of immunohistochemistry over other techniques such as bronchioalveolar lavage, induced sputum or measurement of exhaled NO, to evaluate bronchial inflammation: good morphology, immunoreactivity for increasing number of antibodies, low cost, short procedure. However, light microscopy analysis requires particular attention including multiobserver analysis, blinded counting, and evaluation of both inter- and intraobserver reproducibility $[25,26]$. Computerized analysis can overcome part of these disadvantages provided that the automated recognition system is able to accurately discriminate a positive stain. In the present study, a method of cell recognition based upon the analysis of new criteria, i.e. HD and $\mathrm{H}$ combined with OD is reported. A previous work has shown that primary colours contain not only chromatic information but also nonchromatic data that can contribute to the recognition of a colour [14]. It was found that both $\mathrm{H}$ and $\mathrm{HD}$ had a multimodal pixel distribution significantly different from that of primary colours, allowing the discrimination of shades of colour that can be distinguished by the eye but not by the automated analysis of red, green or blue. The combination of $\mathrm{H}$ and $\mathrm{HD}$ with $\mathrm{OD}$ and morphological criteria such as cell size and shape was used to define and memorize a positive staining for a determined antibody, and to further recognize cells labelled with the same procedure. The method of colour analysis therefore distinguishes the positive staining of a cell from a nonspecific staining of tissue. This is due to differences in both $\mathrm{H}$ and $\mathrm{HD}$, which are measured by the system and compared to the ranging values predetermined by the operator and corresponding to high and low cut-off points. On another hand, the use of both morphological criteria and the proximity index allow the staining of different poles of an elongated cell to be distinguished from those of several adjacent cells. Such a technique enables the automatic counting of a variety of inflammatory cells in bronchial tissue that has a very strong correlation with cell counts performed by independent observers using light microscopy. This correlation depends neither on the type of staining (i.e. membrane or cytoplasm) nor on the primary antibody used to detect a specific marker. In addition, this method allows the limitation of interindividual variations once reference parameters have been set up by the expert. This approach appears to be much quicker and cheaper, particularly for the analysis of specimens with a very high number of cells. Previous studies have described automated systems of cell counting based on OD analysis [13] but true colour 
Table 3. - Automated cell counts in human distal bronchi

\begin{tabular}{|c|c|c|c|c|c|c|c|}
\hline & \multirow{3}{*}{$\begin{array}{c}\text { Total } \\
\text { Cells } \cdot \mathrm{mm}^{-2}\end{array}$} & \multicolumn{6}{|c|}{ Cell type } \\
\hline & & \multicolumn{2}{|c|}{ Epithelium } & \multicolumn{2}{|c|}{ Submucosa } & \multicolumn{2}{|c|}{ Smooth muscle layer } \\
\hline & & Cells $\cdot \mathrm{mm}^{-2}$ & $\%$ & Cells $\cdot \mathrm{mm}^{-2}$ & $\%$ & Cells $\cdot \mathrm{mm}^{-2}$ & $\%$ \\
\hline \multicolumn{8}{|l|}{ Nonsmokers } \\
\hline $\mathrm{NE}+$ & $90.9(32.2-119.4)$ & 14.7 & 4.7 & 128.3 & 66.5 & 45.4 & 23.2 \\
\hline AA1+ & $51.3(23.3-125.6)$ & 9.7 & 1.5 & 100.5 & 47.9 & 58.7 & 51.4 \\
\hline Chymase+ & $32.9(19.3-119.1)$ & 10.6 & 3.5 & 48.8 & 26.0 & 36.1 & 59.4 \\
\hline CD68+ & $150.8(21.7-249.5)$ & 103.0 & 11.5 & 263.9 & 47.7 & 81.8 & 36.5 \\
\hline EG2+ & $42.2(7.4-68.1)$ & 2.5 & 2.8 & 49.3 & 33.2 & 34.6 & 60.3 \\
\hline CD3+ & $42.8(21.6-104.1)$ & 44.5 & 12.2 & 46.6 & 51.3 & 47.4 & 36.1 \\
\hline $\mathrm{d} \varepsilon 2+$ & $27.1(4.5-61.4)$ & 47.1 & $19.0^{*}$ & 29.7 & $40.9^{*}$ & 15.2 & 35.9 \\
\hline \multicolumn{8}{|l|}{ Smokers } \\
\hline NE+ & $72.6(54.1-170.1)$ & 28.5 & 3.1 & 167.1 & 54.9 & 30.4 & 30.5 \\
\hline AA1+ & $86.7(59.2-131.9)$ & 31.5 & 4.9 & 106.0 & 49.3 & 62.5 & 50.7 \\
\hline Chymase+ & $70.3(27.4-109.2)$ & 0.0 & 0.0 & 89.0 & 56.8 & 43.1 & 43.2 \\
\hline CD68+ & $149.9(44.3-250.4)$ & 161.8 & 6.8 & 171.5 & 63.9 & 90.6 & 24.0 \\
\hline EG2+ & $43.6(20.4-138.2)$ & 12.8 & 1.3 & 63.0 & 52.6 & 29.9 & 35.7 \\
\hline CD3+ & $76.3(45.4-193.6)$ & 113.5 & 16.6 & 147.6 & 59.5 & 37.2 & 14.6 \\
\hline $\mathrm{d} \varepsilon 2+$ & $60.5(15.8-100.4)$ & 468.1 & $4.2 *$ & 69.3 & $69.6^{*}$ & 42.4 & 30.4 \\
\hline
\end{tabular}

Values are medians with $95 \%$ confidence limits in parentheses. *: $\mathrm{p}<0.05$, smokers versus nonsmokers (Wilcoxon test). For definitions of abbreviations, see table 2 .

analysis has scarcely been used. Blue-yellow images obtained by filters have allowed the improvement of the automated estimation of epithelial volume [27]. Recently, automated colour recognition has been applied to vessels analysis in tumours [28-30] but not to cell counting as reported in the present study. With respect to colour analysis, the current method takes into account one nonchromatic criterion, i.e., OD, and two chromatic parameters, i.e., $\mathrm{H}$ and HD. The determination of $\mathrm{H}$ and $\mathrm{HD}$ allows the characterization of a colour independently of OD value, and thus the analysis of cell staining independently of light intensity that may vary from peripheral to central areas or according to microscope light.

This automated system of cell recognition was also applied to analyse adjacent sections embedded in glycolmethacrylate, since the thickness of each slide $(2$ $\mu \mathrm{m})$ allows the obtention of several cuts through a single cell. Once detected on a determined area, positive stainings are localized on the adjacent slides and superimposed onto the reference section so that different markers expressed by a single cell can be identified. In bronchial tissue, this analysis was performed for mast cells that are known to contain several types of protease and bear IgE molecules on their surface. A strong correlation was found between the automated analysis and that performed by two independent observers, indicating that colour recognition is a valuable tool for the detection of several markers of a cell phenotype. Study of cell infiltration in tissues requires not only the identification of cell phenotypes but also the determination of intercellular ligands, markers of activation, and adhesion molecules. Double labelling procedures allow such analysis but require a detection system that only binds to one of the primary antibodies and that ensures adequate colour discrimination. For this purpose, the fluorescence technique can be applied to snap-frozen sections using red and green fluorochromes that turn to a yellow stain when cells are double labelled. Colour recognition has already been successfully used to detect such positive staining [14] but morphology is poorly visualized using this technique without phase contrast. On the other hand, fluorochromes are generally short-lived, making the photographic recording of the results a necessity. In this respect, procedures including examination of adjacent sections are easier to control provided that an automated system of cell recognition is used to analyse cell markers, the number of which will only be limited by the size of the cell.

In the present study this automated system of cell recognition was applied to the evaluation of inflammatory cell infiltration of bronchial mucosa. For this purpose, bronchial specimens that were obtained at thoracotomy from subjects with a history of cigarette smoking were

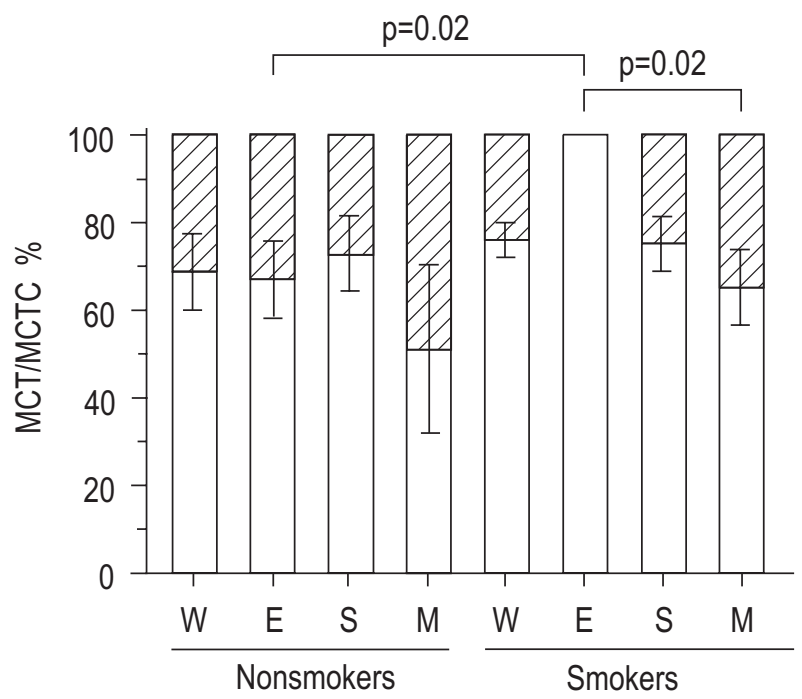

Fig. 5. - Distribution of mast cells containing tryptase (MCT, $\square$ ) and mast cells containing tryptase and chymase (MCTC, $\mathbb{Z}$ ) in bronchial specimens from nonsmokers $(n=5)$ and smokers $(n=6)$. Results are expressed as mean \pm SEM percentage for mast cells in the whole bronchial wall (W), and within the epithelial (E), submucosal (S) or smooth muscle (M) layers. The total number of each cell phenotype has been normalized to $100 \%$. 
investigated. Several studies have provided strong evidence that smokers develop a bronchial inflammatory process composed predominantly of neutrophils, macrophages and lymphocytes [5-7]. Patients involved in the current study had cellular infiltration of bronchial mucosa similar to that previously described for smokers suffering from chronic bronchitis without airflow limitation [5]. Nevertheless, in terms of cell phenotypes, significant differences were not found between the number of macrophages, neutrophils or T-lymphocytes in smoker's bronchial mucosa and that measured in nonsmokers. The absence of a clear difference between the two groups may be related to the slight airflow limitation found in smoking subjects who participated in the study. It also should be noted that bronchi analysed in the present work were peripheral airways for which it has been recently demonstrated that CD8 T-lymphocytes, but not macrophages or neutrophils, are associated with symptoms of chronic bronchitis and airflow limitation [11]. Using the automated analysis of adjacent sections, IgE positive cells that might be involved in smoking-induced airway inflammation were also investigated. It was found that smokers had a significantly higher number of cells bearing the IgE molecule than nonsmokers. This finding may be due, in part, to the increase in mast cell number and, in part, to the increase in T-lymphocytes, both phenotypes having the ability to bear $\operatorname{IgE}[16]$. Several studies have ascribed a role to mast cells in COPD $[10,31]$ although the total number of mast cells within the airway wall does not appear to be related to airway obstruction $[5,6]$. However, different authors have observed an increase in the number of mast cells located in airway epithelium exposed to cigarette smoking $[31,32]$. In addition, the concentration of tryptase, the main mast cell-derived protease, can be elevated in smoker's bronchoalveolar lavage fluid [33]. In the current study, a significant increase in epithelial mast cell numbers of MCT subtype was not found in the smokers group.

In the present report the bronchial inflammation of lung specimens obtained at thoracotomy from smokers and nonsmokers has been examined with an automated method of cell analysis based upon the evaluation of new criteria of colour recognition suitable for cell quantification. The results indicate that this method is valuable for easily assessing inflammation in airways and for analysing the expression of different markers by a single cell in bronchial tissue.

\footnotetext{
Acknowledgements. The authors thank the staff of Service de Chirurgie Thoracique et Service d'Anatomopathologie, Hôpital Haut Léveque, CHU de Bordeaux for the supply of human lung tissue. Also C. N'Guyen for technical assistance.
}

\section{References}

1. Djukanovic R, Lai CK, Wilson JW, et al. Bronchial mucosal manifestations of atopy: a comparison of markers of inflammation between atopic asthmatics, atopic nonasthmatics and healthy controls. Eur Respir J 1992; 5: 538-544.

2. Aalbers R, de Monchy JG, Kauffman HF, et al. Dynamics of eosinophil infiltration in the bronchial mucosa before and after the late asthmatic reaction. Eur Respir J 1993; 6: 840-847.

3. Peroni DG, Djukanovic R, Bradding P, et al. Expression of CD44 and integrins in bronchial mucosa of normal and mildly asthmatic subjects. Eur Respir J 1996; 9: 22362242.

4. Pesci A, Foresi A, Bertorelli G, Chetta A, Oliveri D. Histochemical characteristics and degranulation of mast cells in epithelium and lamina propria of bronchial biopsies from asthmatic and normal subjects. Am Rev Respir Dis 1993; 147: 684-689.

5. Di Stefano A, Turato G, Maestrelli P, et al. Airflow limitation in chronic bronchitis is associated with T-lymphocyte and macrophage infiltration of the bronchial mucosa. Am J Respir Crit Care Med 1996; 153: 629-632.

6. Saetta M, Turato G, Facchini FM, et al. Inflammatory cells in the bronchial glands of smokers with chronic bronchitis. Am J Respir Crit Care Med 1997; 156: 1633-1639.

7. Turato G, Di Stefano A, Maestrelli P, et al. Effect of smoking cessation on airway inflammation in chronic bronchitis. Am J Respir Crit Care Med 1995; 152: 1262-1267.

8. Minshall EM, Hogg JC, Hamid QA. Cytokine mRNA expression in asthma is not restricted to the large airways. J Allergy Clin Immunol 1998; 101: 386-390.

9. Vignola AM, Chanez P, Chiappara G, et al. Transforming growth factor-b expression in mucosal biopsies in asthma and chronic bronchitis. Am J Respir Crit Care Med 1997; 156: 591-599.

10. Pesci A, Rossi GA, Bertorelli G, Aufiero A, Zanon P, Olivieri D. Mast cells in the airway lumen and bronchial mucosa of patients with chronic bronchitis. Am J Respir Crit Care Med 1994; 149: 1311-1316.

11. Saetta M, Di Stefano A, Turato G, et al. CD8+ T-lymphocytes in peripheral airways of smokers with chronic obstructive pulmonary disease. Am J Respir Crit Care Med 1998; 157: 822-826.

12. Pickering JG, Boughner DR. Quantitative assessment of the age of fibrotic lesions using polarized light microscopy and digital image analysis. Am J Pathol 1991; 138: 1225-1231.

13. Wachsmuth ED, Germer M, Paulus K, Persohn E. Automated counting of nuclei in series of conventional liver sections to differentiate hypertrophy and hyperplasia. Toxicol Appl Pharmacol 1993; 121: 264-274.

14. Lamaziere JM, Lavallee J, Zunino C, Larrue J. Semiquantitative study of the distribution of two cellular antigens by computer-directed color analysis. Lab Invest 1993; 68: 248-252.

15. Tunon de Lara JM, Okayama Y, Savineau JP, Marthan R. IgE-induced passive sensitization of human isolated bronchi and lung mast cells. Eur Respir J 1995; 8: 1861-1865.

16. Berger P, Walls AF, Marthan R, Tunon-de-Lara JM. Immunoglobulin E-induced passive sensitization of human airways: an immunohistochemical study. Am J Respir Crit Care Med 1998; 157: 610-616.

17. Britten KM, Howarth PH, Roche WR. Immunohistochemistry on resin sections: a comparison of resin embedding techniques for small mucosal biopsies. Biochem Histochem 1993; 68: 271-282.

18. Walls AF, Jones DB, Williams JH, Church MK, Holgate ST. Immunohistochemical identification of mast cells in formaldehyde-fixed tissue using monoclonal antibodies specific for tryptase. J Pathol 1990; 162: 119-126.

19. Sezan MI. A peak detection algorithm and its application to histogram-based image data reduction. Comput Vision Graphics Image Process 1990; 49: 36-51. 
20. Weszka JS. A survey of threshold selection techniques. Comput Graphics Image Process 1978; 7: 259-265.

21. Bradding P, Roberts JA, Britten KM, et al. Interleukin-4 -5 , and -6 and tumor necrosis factor-alpha in normal and asthmatic airways: evidence for the human mast cell as a source of these cytokines. Am J Respir Cell Mol Biol 1994; 10: 471-480.

22. Bland JM, Altman DG. Statistics Notes. Measurement error and correlation coefficients. BMJ 1996; 313: 41-42.

23. Chinn S. Statistics in respiratory medicine 3. Scale, parametric methods, and transformation. Thorax 1996; 46: 536-538.

24. Bland JM, Altman DG. Statistical methods for assessing agreement between two methods of clinical measurement. Lancet 1986; i: 307-310.

25. Saetta M, Jeffery PK, Maestrelli PWT. Biopsies: processing and assessment. Eur Respir J 1998; 11: 20s-25s.

26. Sont JK, Willems LN, Evertse CE, Hooijer R, Sterk PJ, van Krieken JH. Repeatability of measures of inflammatory cell number in bronchial biopsies in atopic asthma. Eur Respir J 1997; 10: 2602-2608.

27. Schipper NW, Smeulders AW, Baak JP. Evaluation of automated estimation of epithelial volume and its prognostic value in ovarian tumors. Lab Invest 1989; 61: 228-234.
28. el-Salhy M, Sandstrom O, Nasstrom E, Mustajbasic M, Zachrisson S. Application of computer image analysis in endocrine cell quantification. Histochem J 1997; 29: 249256.

29. Ranefall P, Wester K, Bengtsson E. Automatic quantification of immunohistochemically stained cell nuclei using unsupervised image analysis. Anal Cell Pathol 1998; 16: 29-43.

30. Van der Laak JA, Westphal JR, Schalkwijk LJ, et al. An improved procedure to quantify tumour vascularity using true colour image analysis. Comparison with the manual hot-spot procedure in a human melanoma xenograft model. J Pathol 1998; 184: 136-143.

31. Grashoff WF, Sont JK, Sterk PJ, et al. Chronic obstructive pulmonary disease: role of bronchiolar mast cells and macrophages. Am J Pathol 1997; 151: 1785-1790.

32. Lamb D, Lumsden A. Intra-epithelial mast cells in human airway epithelium: evidence for smoking-induced changes in their frequency. Thorax 1982; 37: 334-342.

33. Kalenderian R, Raju L, Roth W, Schwartz LB, Gruber B, Janoff A. Elevated histamine and tryptase levels in smokers' bronchoalveolar lavage fluid. Do lung mast cells contribute to smokers' emphysema? Chest 1988; 94: 119123. 